\title{
The experience of physician supervisors with clerkship students: a qualitative study
}

\author{
Charlotte Silén ${ }^{1}$, Anna Kiessling², Jonas Spaak ${ }^{2}$, Peter Henriksson ${ }^{2}$ \\ ${ }^{1}$ Centre for Medical Education, Department of Learning, Informatics, Management and Ethics, Karolinska Institutet, Sweden \\ ${ }^{2}$ Department of Clinical Sciences, Danderyd Hospital, Division of Cardiovascular Medicine, Karolinska Institutet, Sweden
}

Correspondence: Charlotte Silén, Centre for Medical Education, Department of Learning, Informatics, Management and Ethics, Karolinska Institutet, Sweden. Email: charlotte.silen@ki.se

\begin{abstract}
Objectives: The purpose of this study was to describe fulltime physicians' conceptions of being clinical supervisors when introducing students to professional practice and having dedicated time with their students without the distraction of other clinical duties.

Methods: The study was conducted during 2009 at Danderyd University Hospital in Stockholm, Sweden where 61 physicians have had the role of full-time supervisors. Nineteen of these physicians, both male $(n=9)$ and female $(\mathrm{n}=10)$ varying in age and experience, were interviewed regarding their experience following supervision of firstyear clerkship students which were undertaking five weeks of introductory course in clinical skills. The interviews were transcribed verbatim and thematised using inductive content analysis according to theoretical assumptions of communication theory.
\end{abstract}

Results: Being present in the moment and not having to worry about other clinical duties was identified as the most fundamental theme for supervision. Participants stressed the importance of dedicated time to fulfil their role. Three other themes: being a catalyst for learning; being an expert; and supporting students' sense of coherence, revealed how supervisors support student learning in different ways. Conclusions: Full-time supervision allowed physicians to pay close attention to the student's learning process as well as their interaction with patients or PBL group members. They were able to use their experience and expertise to engage students in their own learning and to give skilful feedback. Furthermore, they were able to create a coherent learning environment for students to realise the true meaning of being a doctor. These factors may become important in design of clinical courses.

Keywords: Clinical supervision, clinical education, undergraduate medical education, qualitative study

\section{Introduction}

The clinical ward, brimming with patients and skilled health care professionals, constitutes a unique environment for medical students to learn about their future vocation. However, just placing medical students in a ward, fresh from the lecture hall, has proven unsatisfactory which has led to them feeling insufficient and out of place. By the same token, clinicians have felt that they had inadequate time or training for supervision of students. ${ }^{1-4}$

Clinical education and supervision in clerkship is part of an entire medical education programme making clerkship a complex activity depending on various demands from the perspectives of the students, the supervisors, the activities on the ward and the university. In recognition of this complexity, a clinical introductory course in the fifth semester of the prequalification medical programme at Karolinska Institutet, Sweden was thoroughly redesigned in 2002. Details of the course have been improved continuously but the basic design has remained the same. One of the major changes was to appoint physicians as full-time clinical supervisors for about 5 weeks during the course. The course design was based on theoretical assumptions about meaningful learning. A problem-based learning (PBL) approach and collaboration in learning was implemented and the students were offered an element of continuity in terms of supervision and time on the ward. ${ }^{5-7}$ Evaluations have shown that the students now rate supervision, course content and possibilities to meet course objectives much higher than before. Physicians supervising in the 
new course also appreciate fulfilling their role as supervisors. Consequently, this has turned into a gratifying task rather then something they wish to avoid. After seven years of positive evaluations from students and supervisors, we were intrigued to try and get a deeper understanding of how these supervisors understand their role in overseeing medical students under the present circumstances.

The obligations of a clinical supervisor will vary in different countries and medical education programmes. Based on the definition of supervision by Kilminster and colleagues, we define the clinical supervisor in this study to be a physician who provides guidance and feedback on matters of personal, professional and educational development in the context of undergraduate experience based clinical education. ${ }^{3}$

Many studies have been carried out which explore the nature of medical students' learning in clinical practice. Nevertheless, only a few have taken into account the complexity of the learning situation in the clinical ward. ${ }^{2-4} \mathrm{~A}$ number of studies also exist regarding the education of supervisors in their ability to teach students. ${ }^{8-12}$ However, less is known about how physicians undertake supervision as well as their perceptions of supervision. ${ }^{13}$ Irby has argued that we need a better understanding of supervisors' knowledge and reasoning with regards to what enabled them to be good supervisors; how they used their knowledge to target their learners' needs and how they made learning meaningful and enjoyable. ${ }^{14}$ Some studies suggest that good supervision depends on the quality of relationship and the interaction between supervisor and trainee. ${ }^{3,4}$ Young and colleagues found that students particularly valued learning opportunities and quality time with physicians during which they practised clinical skills. ${ }^{4}$

Other factors that were appreciated by students were opportunities to receive focused feedback, ${ }^{3,4}$ continuity related to supervisors and time to reflect on their experiences in clerkship. ${ }^{3,15}$ Furthermore, it has been found important to create a nonthreatening learning environment for students which may otherwise prevent them from admitting their lack of knowledge in certain areas since they strive to appear as competent as possible. As a result, this may hinder them from utilising opportunities to learn. ${ }^{3,16}$ From a supervisor's perspective, the major obstacle to good supervision was the lack of time which caused stress when they had concurrent clinical and teaching demands. ${ }^{2,3,17}$ Other impediments reported in the literature included insufficient pedagogic training regarding students' learning, poor support, insufficient leadership and recognition by hospital staff and notably, a perceived lack of inclusion among faculty. ${ }^{17-19}$

The aim of the present study was to elucidate physicians' perceived and latent conceptions of their roles as supervisors of medical students when they had the opportunity of solely focusing on supervision. A deeper understanding of supervision from supervisors' own perspectives should provide valuable information on the design of basic clinical courses and the planning of educational activities for supervisors.

\section{Methods}

\section{Setting and sample}

Danderyd University Hospital in Sweden provides acute and elective care to 455,000 patients and is responsible for clinical clerkship in internal medicine for 180 medical students at undergraduate level each year. The students start the clinical part of their training at the hospital with a five-week course in the fifth semester, out of a total of eleven. During this course, the students work in groups of 7 to 8 , applying a $\mathrm{PBL}$ approach where they practice fundamental clinical skills; learn how to take a patient history and how to examine patients for the first time. The same supervisor followed his or her group during all these different learning activities.

In total, 61 physicians now have the experience of acting as full-time supervisors in this particular course. Almost all of them were employed as physicians by the Department of Internal Medicine or Cardiology. They have a median of 9 years of experience as physicians. Nineteen of these physicians, both male $(n=9)$ and female $(n=10)$ were purposively sampled and were asked to participate in group interviews. All agreed to participate in the study. Participants were aged 30 to 48 years $($ mean $=37.5$; $\mathrm{SD}=$ 5.4). Participants were divided into four groups. Care was taken to ensure that each group contained a mix of genders, age groups and individuals with different levels of work experience.

\section{Study design}

The study was guided by constructivist theories of teaching and learning. A qualitative approach was chosen to gain different possible aspects of the supervisors' perceived and latent conceptions. Through the communication with, and the analysis of utterances of these respondents who had experienced being supervisors, we got an understanding of their perceptions.

In a set of semi structured interviews, a core number of questions were explored and respondents were encouraged to express themselves freely and openly where the interviewer asked for clarification or meaning of straight-forward or ambiguous answers. ${ }^{20}$ Group interviews were performed in order to get rich data from the interactions between the respondents. The method takes into account manifest as well as latent content in the interviews. The manifest content, i.e. what was actually said in the interview, was presented in categories, while themes were seen as expressions of latent content, which was the interpretation of the text.

\section{Data Collection}

In 2009, four group interviews were performed with each 
interview lasting for about 1 hour and $15 \mathrm{~min}$. One of the authors (CS) conducted all interviews in presence of one of the other authors (JS). To get rich data and ensure trustworthiness, the respondents understanding of being a supervisor in the present setting was probed in depth. At first, each group was asked to give a general description of the course. Subsequently the interview was focused on three domains to include: 1) the supervisors' thoughts of the students learning during the course and their own role, 2) their function in supporting this learning and 3) the personal meaning of being a supervisor.

\section{Data Analysis}

The interviews were recorded, transcribed verbatim and checked against the audio-recording for accuracy. The transcripts regarding participants' thoughts on their role as supervisors and their function in supporting student learning were extracted and unified into a single text, which formed the unit of analysis. An inductive content analysis was performed as previously described..$^{21}$ This was based on theoretical assumptions related to communication theory as described by Watzlawick. ${ }^{22}$ Data was analysed with the aim of highlighting supervisors' conceptions of their own function. Firstly, meaning units were identified, condensed and abstracted into categories and subcategories. Next, the categories were interpreted and the underlying meaning, i.e., the latent content of the categories, were formulated into themes. Since all of the authors have different background and perspectives, to ensure credibility, all categories and themes were discussed until all authors were in agreement.

\section{Ethical Considerations}

The work was carried out in accordance with the Declaration of Helsinki and was approved by the Ethics Committee of Karolinska Institutet. Prior to each interview, all respondents were informed that participation was voluntary and answers were confidential.

\section{Results}

Four themes were identified in the analysis. Examples of meaning units, categories and subcategories underpinning these themes are presented in Table 1. "Being present" was identified as a fundamental prerequisite for providing supervision. The other three themes: being a catalyst for learning; being an expert; and supporting students' sense of coherence clarified how the supervisors, in different ways, supported students to reach not only the goals of the course, but also to acquire the skills and behaviours needed in a ward context and possibly their future vocation.

\section{Being present in the moment}

Being present formed the basis of the supervisors' role in the present setting. The physicians emphasised, very strongly, the importance in having dedicated time to act as supervisors:
"I had uninterrupted time to devote to this group, and could

follow them from the beginning till the end" - Female 2

This prerequisite created a possibility to be present in the moment and allowed them to pay full attention to the students' performance with regards to the patient. In addition, they were able to closely oversee in-group activities such as the interactions between group members as well as the interactions between students and patients. The experience of being present in the moment stood out as extremely important in enabling physicians to identify themselves as a supervisor and allowed to concentrate on creating fruitful relationships and contribute to the students' learning.

Allocated time to become solely a supervisor was important to the physician to release their mind and to concentrate on supervision, instead of having to worry about time for clinical duties:

"Instead of teaching part time at the same time as doing the daily work, we could focus on the group and [really] being there" - Male 2

The physical presence of physicians in different learning situations resulted in opportunities that allowed them to direct their full attention towards the situations that were related to students' learning. They could thus pay full attention to what students said or did and interpret what happened and to act accordingly. Being present enabled the supervisor to follow and adapt to the students' learning processes and to become aware of the students' progression towards reaching their goals. The possibility to create a relationship with the students was stressed as important in these interactions.

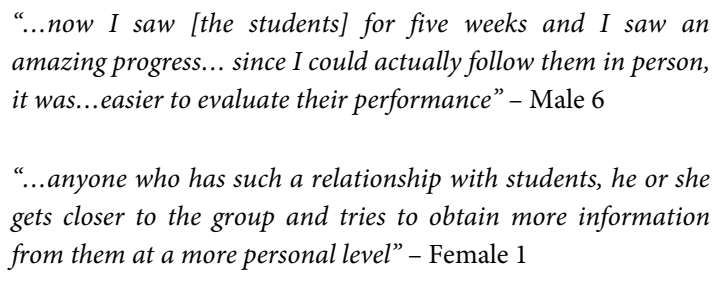

"... anyone who has such a relationship with students, he or she gets closer to the group and tries to obtain more information from them at a more personal level" - Female 1

\section{Being a catalyst for learning}

Given the presence in the moment, we identified the catalysing function as a specific and separate quality of the supervisors' experience. Being a catalyst for learning indicated that the supervisor used his or her professional experience and knowledge to engage students in their own learning process. The students were guided and coached by the supervisor, but the reasoning and the actual work were left to the students. Being a catalyst for learning required the supervisor to be aware of and to utilise available methods to support student learning in their first meetings with patients and also in their introduction to the ward context. It included creating high-quality learning situations (such as tailored student-patient meetings) and opportunities for 
Table 1. Process of content analysis illustrated by examples of condensed meaning units, subcategories and categories that correspond to the four themes

\begin{tabular}{|c|c|c|c|}
\hline Meaning unit (examples of each theme) & Category & Subcategories & Theme \\
\hline $\begin{array}{l}\text { "one had uninterrupted time with this group, and } \\
\text { could follow them from the beginning ... until the } \\
\text { end"- Female } 2\end{array}$ & $\begin{array}{l}\text { Allocated time for supervision } \\
\text { create a foundation for interacting } \\
\text { with students }\end{array}$ & $\begin{array}{l}\text { To "see" the students in relation to their } \\
\text { learning situation in the clinic. } \\
\text { Build relationship with students }\end{array}$ & To be present \\
\hline $\begin{array}{l}\text { "... not too complicated patients, not too many } \\
\text { diseases and so. It should not become too } \\
\text { complicated for them (the students) when they take } \\
\text { their history, then they can't sort it out."- Male } 8\end{array}$ & $\begin{array}{l}\text { To use and create learning } \\
\text { encounters to facilitate each } \\
\text { students learning process }\end{array}$ & $\begin{array}{l}\text { Feedback based on students' perfor- } \\
\text { mance } \\
\text { To select suitable patients and learning } \\
\text { encounters }\end{array}$ & $\begin{array}{l}\text { To catalyse } \\
\text { learning }\end{array}$ \\
\hline $\begin{array}{l}\text { "explain what is relevant or not, that they can make } \\
\text { connections between what they have learnt in } \\
\text { theory with what actually matters...., they don't know } \\
\text { what is useful in clinical practice, what is more } \\
\text { important"- Female } 8\end{array}$ & $\begin{array}{l}\text { To use physician expert knowledge } \\
\text { to facilitate the students learning of } \\
\text { the profession }\end{array}$ & $\begin{array}{l}\text { Support translation of theoretical } \\
\text { knowledge to clinical practice } \\
\text { To act as a professional role model }\end{array}$ & To be an expert \\
\hline $\begin{array}{l}\text { "... and see how the group grows and mature at the } \\
\text { same time as you see each individual, how they } \\
\text { grow too... And there one has a large responsibility } \\
\text { as a supervisor... to see the level in the whole } \\
\text { group... to ensure that the group make progress... } \\
\text { someone a little weaker, someone stronger... } \\
\text { growing into a good balance."- Male } 7\end{array}$ & $\begin{array}{l}\text { Align learning of theoretic } \\
\text { knowledge, skills and performance } \\
\text { and relate that to future profession } \\
\text { as physician. }\end{array}$ & $\begin{array}{l}\text { Create coherence between different } \\
\text { learning activities for the students to } \\
\text { reach their learning goals. } \\
\text { Giving students responsibilities and } \\
\text { permission to act as physicians under } \\
\text { supervision }\end{array}$ & $\begin{array}{l}\text { To support } \\
\text { students' sense } \\
\text { of coherence }\end{array}$ \\
\hline
\end{tabular}

students to interact with ward staff. Finding and selecting suitable patients in the ward was found to be an important part of the catalyst role. The student-patient meeting should be staged according to the student's current skills and needs.

\footnotetext{
“...neither complex patients nor ones with too many diseases. Taking history should not become complex for [the students]; otherwise they can't sort it out" - Male 8
}

The catalyst role required physical presence to keep an eye on the student continuously in order to ensure that the student-patient interaction went accordingly. It also entailed observing students' performance and the importance of giving feedback:

"When my student was taking the medical history and examining his patient, I was intently listening and quietly observing. And then I gave him feedback on how he could have done better" - Female 1

Small student-groups and ample time dedicated to supervision enabled teachers to catalyse learning by seizing opportunities required for learning when they occurred. When, for instance, the patient presented something unexpected, the supervisor could turn this into a learning experience.

\section{Being an expert}

The supervisor as an expert emerged as another important theme. The physician used their qualified medical and tacit knowledge to give skilful feedback and instructions guided by his/her clinical experience. This theme was characterised by how physicians share knowledge, experiences and other aspects of the medical profession with the students. The supervisors stressed the importance of supporting students' transition from the theoretical knowledge of basic science, to real clinical practice and the introduction of students into their role as physician. They were further involved in educating students with skills required for an effective patient centred clinical examination. The supervisors underline how they used their clinical expertise when they observed the students and when they gave feedback. They described a need to help students change focus from knowing the fundamental mechanisms of body to selecting and structuring the most relevant parts of this knowledge when interacting with patients:

\footnotetext{
"...to explain what is relevant or not, that they can make connections between what they have learnt in theory with what actually matters...., they don't know what is useful in clinical practice, what is more important" - Female 8

"...to teach them how to structure ... when they are handling clinical cases, they sometimes wander off the point... is about helping them to get back on track" - Male 9
}

During the course, the supervisors came to realise that they were viewed as role models, clinically as well as professionally, both in the contact with patients, and in the collaboration with other professions on the ward.

$$
\begin{aligned}
& \text { "...one realised that they will replicate exactly what I do..." } \\
& \text { - Male } 3
\end{aligned}
$$

As role models, they adapted their behaviour depending on situation. They considered themselves to mediate both rewarding and social parts of being a physician and to introduce students to all practical aspects implicit in the ward, such as dress-code, hierarchy, "coffee-room rules" etc. They instructed students on the practical and fundamental aspects of physical examination, such as how to wear a stethoscope, to professionally introduce oneself to a patient, and how to encourage patient's participation. 
"...you get an opportunity to show what is fun with this, which is a bit like detective-work and, yes, that you have so much contact [with the student] that you can express it" - Female 4

The respondents reported that they became aware that they were role models and this was experienced as one of the most rewarding aspects of being a supervisor.

"Right there at the [end of the course] last part I got one of those, I don't know, heart-warming sensations, I look and read their patient files, and it feels like reading my own" - Male 8

\section{Supporting students' sense of coherence}

This theme brings forward the supervisors' intention to support the students' development of a professional sense of coherence. This relates to the student's ability and skills to comprehend priorities and manage clinical work and to perceive its meaning as a physician. The supervisors described how they used the course design and local context to create a coherent learning environment for students. To follow the same student group over time during different learning activities made it possible to support the students in comprehending what physicians do, in managing their own performance in the work place and to perceive learning activities as meaningful.

The supervisors expressed their intentions to reconcile different learning activities in order to help students link different information and experiences and facilitate the creation of coherent understanding. When they met patients at the ward, the supervisor referred back to discussions during the preceding PBL group sessions or lectures, and similarly, in problem based-group sessions they tied the discussion to previous patient meetings.

They also used the group to share and link individual students' experiences, clinical reasoning strategies, gained knowledge and acquired clinical skills:

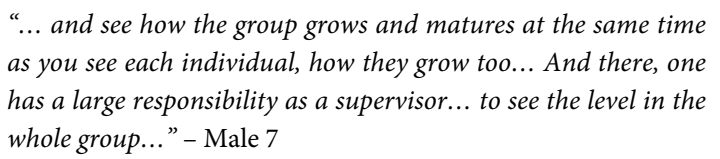

Taking responsibility of students' learning process was perceived as an important part in the support of the students' creation of wholeness and sense of coherence. This included visualising the link between basic science, clinical knowledge and skills, and a particular patient's problems. They expressed the importance of establishing boundaries to help students retain focus on training of basic skills in history taking, physical examination and clinical reasoning.

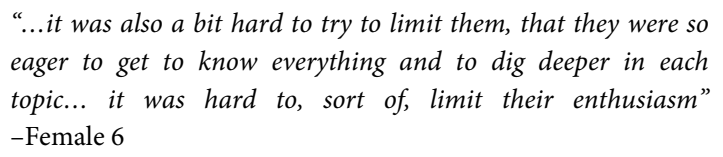

Supervisors endeavoured to create professional relationships between themselves as physicians and the students as future physicians. This was described as an engagement in the students' development and a curiosity in how they reflected and acted as individuals. It was further expressed as giving students responsibility and permission to act as physicians under supervision rather than just being passive observers.

“...saying things like: 'let's go through this on Friday' or 'look at your notes, they are great'... in doing so, they get feedback, making them burn with enthusiasm..."

"...how much responsibilities I feel each individual can handle? Maybe I start with giving some easier tasks that we check through together. Then I usually feel how much they can handle" - Male 5

\section{Discussion}

Our most significant finding was that "being present" enabled and nurtured behaviour in clinical supervisors that in many respects was consistent with what most course-designers aim for in clinical training. The main requirement was to enable the supervisors' presence by allocating time for supervision, but also that the structure of the course involved the supervisors in the students' theoretical studies (such as PBL groups), skills training and encounters with patients. In this study, the supervisors' conception of their different roles and functions emerged. They tended to keep the focus on students' learning, sometimes acting as a catalyst in the learning process and sometimes using and contributing with their expert knowledge. We also found that they had a function to help students find a professional sense of coherence in the learning situation and in their future profession as physicians.

In other studies the importance of allocated time has been brought forward. ${ }^{2,3,17}$ In our study, the notion of presence is clearly related to amount of dedicated time that was allocated for supervision. The supervisors were allowed to prioritise supervision as they didn't have competing clinical duties. The physicians in our study put their full attention on the students. Their perception were directed outwards and created a basis of being present in a real situation. This reasoning could be related to the gestalt psychologists' definition of figure and background in a perceptual field. ${ }^{23}$ According to gestalt psychologists, an individual's awareness is related to a perceptual field where some aspects form the background and other aspects are in the foreground. The figure is in the foreground of the person's awareness. In this case, this means that the students' learning constituted the figure, i.e. the foreground of the supervisors' awareness; whereas their own role as physicians and supervisors became the background.

The supervisors used all their senses to observe and interpret what the students were doing. Knowing their own duties as physicians are taken care of seems to be crucial for this process. The importance of a good relationship between 
the supervisor and students and a non-threatening learning environment has previously been described. ${ }^{3,4,16}$ In this case, the supervisors seemed to be genuinely interested in building high-quality relationships by investing their full attention in students.

By being present the supervisors adapted their behaviour aiming to stimulate students to engage in learning processes on their own. This was shown in all themes but with different starting points and aims.

The aspects of acting as an expert physician and role model appeared to be something exceeding the more traditional role as expert supervisor. In our view, a traditional role mainly includes instructions and bedside teaching. The supervisors in this study stressed the use of their own expertise to support the students' transition from basic science to clinical practice and the role as a physician. The supervisors recognised themselves as being expert role models in different situations and used this to facilitate student learning. Even more tacit learning issues, like becoming part of the staff at the ward, was pinpointed as an important part of being a role model. This way of thinking about supervision could be understood to have the same pedagogical intention as that of a catalyst. In both functions, the supervisor aimed to facilitate learning and not primarily to transfer knowledge. In the expert role, they used their expert knowledge to give skilful feedback and instructions guided by clinical experience. In the catalyst role, the supervisor initiated and engaged students in learning processes of their own as well as in creation of opportunities to interact with patients.

The basic idea of facilitating student learning was also presented in the theme "to support students' sense of coherence". Antonovsky ${ }^{24,25}$ first described the construct "sense of coherence". He stated that an individual's sense of comprehensiveness, manageability and meaningfulness in a situation is crucial to behaviour. To act professionally as a physician in clinical decision-making, integrating scientific evidence with concrete and abstract components of each patient in routine practice is a complex task. Thus, learning to become a physician has to include the gaining of a professional sense of coherence. We found the supervisors awareness of this to be a very interesting result. In the present study we saw that the supervisors adopted a responsibility to create a kind of coherence, not only the bits and pieces of their own specialty. They showed an interest in the students' learning progress and found it stimulating to observe how students became a part of the clinical setting and began to contribute to patient care activities.

We could discern an overriding view on learning permeating the themes that resonated well with other curriculums designed with a focus on using student centred approaches..$^{5-7}$ A main assumption was that supervisors facilitate learning instead of transferring knowledge.

The learner's processing of information into own understanding as well as receiving feedback was emphasised in the learning process. It was remarkable that the supervisors almost by themselves used this approach. They had not been specifically trained (except on how to lead the PBL groups) and still their beliefs of functioning as supervisors very strongly carried the characteristics of a student centred approach. This fact raised several questions: are there similarities between the supervisor's role in student-centred learning and the physician's role in building a relationship to the patient? Is this a feature of this particular setting?

Does allowance to prioritise time and commitment on student learning enable the physicians to use many years of own "embodied knowledge" of how to learn a profession in their teaching? These questions are important to reflect on when discussing transferability to other contexts and as important hypotheses for future studies.

Yearly written evaluations showed that the students were satisfied and that the supervisors found this particular course set up rewarding in many aspects. The allocated time to be a supervisor and the design of the course seemed to be key factors to reach high quality in clinical supervision. The supervisors were responsible for PBL group work, instructions of hands-on skills and introduction to patient encounters and clerkship. To follow the students in several activities gave the supervisors a good understanding of the students' learning situation. The design created time for the supervisor to reflect, to follow the students' progress and the supervisors themselves got continuous feedback. On the whole, the design seemed to answer some problems described in the literature related to supervision in general ${ }^{2}$, ${ }^{3,5,17}$ and on how to design clerkship. ${ }^{26}$

\section{Limitations of the study}

We believe that the number of participants that were recruited to this study was sufficient in size. This is because we discovered that collection of data from new participants confirmed previously collected data rather than adding new information, thus saturating our findings. This gave us confidence that the description of the phenomena has been captured. To maintain the research integrity and honesty and enhance the quality, it is necessary to consider any researcher effect that may have risen in this study.

One limitation of this study is that three of the authors, ( $\mathrm{PH}, \mathrm{AK}$ and JS) have been involved in the course and could thereby possibly influence the findings. However knowledge of physician roles in acute hospital based care and of the course construct has been necessary in the analysis. The fourth researcher (CS) had not been involved in the course. All authors were engaged in the analysis and different experiences made it possible to challenge each other's assumptions and constantly return to data for confirmation of interpretations. This investigator triangulation ${ }^{27}$ could be seen as one way of ensuring trustworthiness. However there is always a risk that the authors might impose meaning to the results. Another limitation is that the study has been 
conducted only at one hospital. In order to use the results in other medical educational programmes, the context of this study has to be taken into account and considered in relation to the context where they are going to be applied.

\section{Conclusion}

Allocated time to prioritise supervision created situations where the physician became fully present, enabling them to give complete attention to the students learning processes, act to catalyse learning, and used gained expertise to support the students' transition from knowing basic science to participate in clinical practice. In their role as supervisors, physicians described their professional experience as background, and the students' learning to the foreground with regards to gestalt theory of visual perception. Our study highlights the importance of taking the complexity of the clinical context into account when planning clinical teaching. Enabling physicians to entirely focus on supervision resulted in high quality learning for students. In the model studied here, both the supervisors and the students got the opportunity to experience a sense of coherence related not only to the aim of the course but also in alignment with the overall objective of becoming a clinician.

\section{Acknowledgments}

We wish to thank all supervisors for sharing their thoughts with us. Financial support was provided through the regional agreement on medical training and clinical research (ALF) between Stockholm County Council and Karolinska Institutet, Sweden.

\section{Conflict of Interest}

The authors declare that they have no conflict of interest.

\section{References}

1. Yedidia MJ, Schwartz MD, Hirschkorn C, Lipkin M, Jr. Learners as teachers: the conflicting roles of medical residents. J Gen Intern Med. 1995;10(11):615-23.

2. Morrison EH, Shapiro JF, Harthill M. Resident doctors' understanding of their roles as clinical teachers. Med Educ. 2005;39(2):137-44.

3. Kilminster S, Cottrell D, Grant J, Jolly B. AMEE Guide No. 27: Effective educational and clinical supervision. Med Teach. 2007;29(1):2-19.

4. Young L, Orlandi A, Galichet B, Heussler H. Effective teaching and learning on the wards: easier said than done? Med Educ. 2009;43(8):808-17.

5. Barrows H, Tamblyn, R. Problem-Based Learning. An approach to medical education. New York: Springer Publislishing Company; 1980.

6. Mayer R. Rote versus meaningful learning. Theory Into practice. 2002;41(4):226 - 32 .

7. Silen C, Uhlin L. Self-directed learning- a learning issue for students and faculty! Teaching in Higher Education. 2008;13(4):461 - 75.

62
8. Dewey CM, Coverdale JH, Ismail NJ, Culberson JW, Thompson BM, Patton CS, et al. Residents-as-teacher programs in psychiatry: a systematic review. Can J Psychiatry. 2008;53(2):77-84.

9. Morrison EH, Rucker L, Boker JR, Gabbert CC, Hubbell FA, Hitchcock MA, et al. The effect of a 13-hour curriculum to improve residents' teaching skills: a randomized trial. Ann Intern Med. 2004;141(4):257-63.

10. Morrison EH, Rucker L, Boker JR, Hollingshead J, Hitchcock MA, Prislin MD, et al. A pilot randomized, controlled trial of a longitudinal residents-as-teachers curriculum. Acad Med. 2003;78(7):722-9.

11. White CB, Bassali RW, Heery LB. Teaching residents to teach. An instructional program for training pediatric residents to precept third-year medical students in the ambulatory clinic. Arch Pediatr Adolesc Med. 1997;151(7):730-5.

12. Edwards J, Friedland J, Bing-You R. Residents' teaching skills. New York: Springer Publisher Company; 2002.

13. Stenfors-Hayes T, Hult H, Dahlgren LO. What does it mean to be a good teacher and clinical supervisor in medical education? Adv Health Sci Educ Theory Pract. 2011;16(2):197-210.

14. Irby DM. Teaching and learning in ambulatory care settings: a thematic review of the literature. Acad Med. 1995;70(10):898-931.

15. Norris TE, Schaad DC, DeWitt D, Ogur B, Hunt DD. Longitudinal integrated clerkships for medical students: an innovation adopted by medical schools in Australia, Canada, South Africa, and the United States. Acad Med. 2009;84(7):902-7.

16. Macallan DC, Kent A, Holmes SC, Farmer EA, McCrorie P. A model of clinical problem-based learning for clinical attachments in medicine. Med Educ. 2009;43(8):799-807.

17. Seabrook MA. Medical teachers' concerns about the clinical teaching context. Med Educ. 2003;37(3):213-22.

18. Mann KV, Holmes DB, Hayes VM, Burge FI, Viscount PW. Community family medicine teachers' perceptions of their teaching role. Med Educ. 2001;35(3):278-85.

19. Stone S, Ellers B, Holmes D, Orgren R, Qualters D, Thompson J. Identifying oneself as a teacher: the perceptions of preceptors. Med Educ. 2002;36(2):180-5.

20. Kvale S, Brinkmann S. InterViews : learning the craft of qualitative research interviewing. Los Angeles: Sage Publications; 2009.

21. Graneheim UH, Lundman B. Qualitative content analysis in nursing research: concepts, procedures an measures to achieve trustworthiness. Nurse Educ Today. 2004;24(2):105-12.

22. Watzlawick P, Beavin JH, Jackson DD. Pragmatics of human communication: a study of interactional patterns, pathologies, and paradoxes. New York: Norton; 1967. 
23. Koffka K. Principles of Gestalt Psychology. New York: Harcourt; 1935.

24. Antonovsky A. Health, stress, and coping. San Francisco: Jossey-Bass; 1979.

25. Antonovsky A. The structure and properties of the sense of coherence scale. Soc Sci Med. 1993;36(6):725-33.
26. O'Brien BC, Poncelet AN. Transition to clerkship courses: preparing students to enter the workplace. Acad Med. 2010;85(12):1862-9.

27. Patton MQ. Qualitative research and evaluation methods. 3rd ed. London: SAGE; 2002. 